NBER WORKING PAPER SERIES

\title{
MYOPIA AND THE EFFECTS OF SOCIAL SECURITY AND CAPITAL TAXATION ON LABOR SUPPLY
}

\author{
Louis Kaplow \\ Working Paper 12452 \\ http://www.nber.org/papers/w12452 \\ NATIONAL BUREAU OF ECONOMIC RESEARCH \\ 1050 Massachusetts Avenue \\ Cambridge, MA 02138 \\ August 2006
}

I am grateful to Steven Shavell and NBER workshop participants for comments, Stephanie Gabor and James Kvaal for research assistance, and the John M. Olin Center for Law, Economics, and Business at Harvard University for financial support. The views expressed herein are those of the author(s) and do not necessarily reflect the views of the National Bureau of Economic Research.

(C2006 by Louis Kaplow. All rights reserved. Short sections of text, not to exceed two paragraphs, may be quoted without explicit permission provided that full credit, including (C) notice, is given to the source. 
Myopia and the Effects of Social Security and Capital Taxation on Labor Supply

Louis Kaplow

NBER Working Paper No. 12452

August 2006

JEL No. D11, D91, H21, H24, H55, J22

\begin{abstract}
Myopia is increasingly believed to be a significant determinant of behavior and also plays a central role in justifications for social security and policies toward the taxation of capital. It is important, however, to account for labor supply effects, particularly in light of the preexisting distortion due to labor income taxation. For example, might even actuarially fair social security have the highly distortionary effect of a tax on top of an existing tax (the income tax) because myopic individuals give excessive weight to present levies on earnings that finance distant future benefits? Similarly, might greater reliance on capital rather than labor income taxation be attractive because collections are in the future rather than when earnings are received? To answer these and other questions, this article analyzes the effect of such policies on labor supply in a model that explicitly incorporates myopic decision-making. Many of the results may seem counterintuitive. In most respects, even with myopia, social security has qualitatively different effects than those of a tax levied on top of an existing tax. Both social security and capital taxation may cause labor supply to rise or fall when individuals are myopic, depending on the curvature of individuals' utility as a function of consumption. Moreover, whatever is the sign of these effects under one assumption about how myopia relates to labor supply decisions, the sign is reversed under the other assumption that is considered. Additionally, some interventions have a first-order effect on labor supply from the outset but others do not, and some labor supply effects rise with the magnitude of the intervention whereas others fall.
\end{abstract}

\author{
Louis Kaplow \\ Harvard Law School \\ Hauser 322 \\ Cambridge, MA 02138 \\ and NBER \\ moverholt@law.harvard.edu
}




\section{Introduction}

Economists have long been interested in the possibility that individuals may behave myopically. See, for example, Strotz (1956). Increasingly in the past decade, researchers have emphasized myopia as an explanation for savings behavior, including notably those features that have been difficult to reconcile with idealized models of lifecycle maximization. See, for example, Laibson $(1996,1997)$ and the surveys by Bernheim (2002) and Bernheim and Rangel (2005). Empirical work has focused on such subjects as whether individuals' retirement savings are adequate and, relatedly, the existence of and explanation for a significant drop in consumption upon retirement. ${ }^{1}$

It is also appreciated that myopic savings behavior may have normative implications. Laibson (1996) estimates that correctives for inadequate savings due to myopia could raise individuals' lifetime welfare to an extent equivalent to almost an additional year's worth of income. Social insurance and tax provisions for retirement savings seem motivated in part by the concern that shortsighted individuals may inadequately provide for themselves. Accordingly, economists' recently increased attention to social security and longstanding interest in optimal capital taxation should be extended to incorporate myopic behavior.

The present study pursues such an inquiry with an emphasis on the implications of myopic savings behavior for labor supply. ${ }^{2}$ The subject of labor supply is significant in itself and is especially important in light of the preexisting distortion due to labor income taxation. Although labor supply in general - and how it may be affected by social security and capital taxation - has been studied extensively, it is important to consider how the analysis changes if it is assumed that savings decisions are myopic.

Regarding social security, if mandatory contributions, typically a function of labor income, are viewed by individuals as an additional tax, labor supply effects should be highly significant because payroll taxes that fund social insurance are of a similar order of magnitude to income taxes. Following the rule of thumb that distortion is proportional to the square of the tax rate, the total distortion would quadruple. Furthermore, even an actuarially fair social security

${ }^{1}$ See, for example, Kotlikoff, Spivak, and Summers (1982), Banks, Blundell, and Tanner (1998), Engen, Gale, and Uccello (1999), Moore and Mitchell (2000), Bernheim, Skinner, and Weinberg (2001), Scholz, Seshadri, and Khitatrakun (2004), and Aguiar and Hurst (2005).

${ }^{2}$ No attempt is made here to undertake a complete welfare analysis of any particular policy. In order to do that, one could first examine the welfare effects of a policy ignoring changes in labor supply and then supplement the analysis accordingly. Importantly, labor supply affects government revenue because the existence of an income tax; in standard optimization problems, this welfare effect would be determined, at the margin, by the product of the rate of change in revenue (equal to the rate of change in labor supply times the pertinent marginal tax rate) and the shadow price on the government's revenue constraint. The present article's focus on labor supply effects is motivated in significant part by this formulation of the social maximization problem. 
retirement scheme, not in itself a tax, might be imagined to have similar effects to a current tax on labor if individuals are significantly myopic, for the contributions are extracted from earnings in the present whereas the benefits they finance are in the distant future. Although prior theoretical literature, such as Diamond and Mirrlees (1978, 1986, 2007), has examined a number of respects in which social security may influence retirement decisions, labor supply during working years has received more limited scrutiny. See, for example, Diamond (2002) and the survey by Feldstein and Liebman (2002). ${ }^{3}$ In particular, it has not been systematically analyzed for the case in which individuals are myopic. Yet this case is a natural one to consider in light of the fact that myopia is thought to provide one of the most important justifications for the existence of social security.

Regarding the taxation of capital, it is understood that such taxation serves indirectly as a tax on labor and thus contributes to the distortion of labor supply. To hold the overall level of taxation on labor supply constant, one can examine capital taxation as a form of differential commodity taxation, where different commodities correspond to consumption in different time periods. Atkinson and Stiglitz (1976) showed that, in the presence of an optimal income tax, no differential taxation is optimal when commodities as a whole are weakly separable from labor, with the implication that capital should not be taxed. However, taxes on capital - or, equivalently, differential taxes on future consumption - are ordinarily levied in the future, raising the possibility that they may have less of an effect on the current labor supply of myopic individuals. Perhaps deferred taxation generally, whether substituting a cash-flow consumption tax for a tax on wages as earned or shifting from the taxation of earnings to the taxation of capital, would have a favorable effect on labor supply when individuals are myopic. Relatedly, perhaps the subsidization of capital income, which may otherwise appear attractive as a counterweight to myopic savings decisions, will have an offsetting cost of increasing labor supply distortion. To determine whether these and other conjectures are valid, it is necessary to revisit prior analysis of capital taxation, incorporating myopia explicitly.

This article analyzes the effects of social security and capital taxation (or subsidization) on labor supply in a setting in which individuals' consumption allocation decisions are myopic. Because this is a preliminary investigation of a complex problem, it will focus on a fairly simple model that highlights central issues but abstracts from a number of complications. Accordingly, the analysis will employ a standard two-period model with separable utility, wherein individuals make only two decisions: how much labor to supply in the first period and how to allocate disposable income between the two periods. Individuals will be subject to a linear income tax on their earnings and also to a social security regime in the first variation and to a tax or subsidy on capital income (modeled as a differential tax on consumption in the two periods) in the second variation. Consumption decisions are assumed to exhibit a simple form of myopia wherein

${ }^{3}$ Prior work that examines aspects of the interaction between social security and labor supply - much based on the absence of perfect tax-benefit linkage - includes Auerbach and Kotlikoff (1987), Browning (1985), Burkhauser and Turner (1978, 1985), Gordon (1983), and Moffitt (1987). See also Diamond and Köszegi (2003) on myopia and retirement and Feldstein (1985) on myopia, social security, and savings. 
excessive weight is placed on first-period consumption. For labor supply, two cases are considered: when labor supply decisions exhibit the same myopia as consumption decisions, and when labor supply decisions are nonmyopic but are made with an awareness that consumption will be allocated myopically.

Section 2 examines social security. To isolate the effects of myopia, actuarially fair schemes are considered. Given individuals' myopic consumption decisions, the direct effect of social security's forced-savings feature is to raise welfare. When labor supply decisions are myopic, social security may raise or reduce labor supply, depending on the curvature of individuals' utility functions: Labor supply falls on account of social security reducing myopic individuals' perceived value of disposable income, but it rises because of the relatively greater effect of social security on the perceived marginal utility of consumption in the first period. Importantly, as the forced-savings constraint just begins to bind, there is no first-order effect on labor supply, even though there is a first-order welfare gain in improved consumption allocation. In this respect, despite the existence of even significant myopia, the social security "tax" does not behave as a tax imposed on top of a preexisting tax (the linear labor income tax in this model): A small pure additional tax, unlike the social security tax here, would have a first-order effect on labor supply and thus on distortion.

Moving to the case in which individuals' labor supply decisions are nonmyopic, the sign of the effect of social security on labor supply reverses. That is, in cases in which the effect on labor supply is negative (positive) with myopic labor supply, it is positive (negative) with nonmyopic labor supply. This difference results because nonmyopic individuals view social security's forced savings positively, which reverses both the direct effect of social security on the value of consumption and the indirect effect on marginal utilities of consumption in the two periods, as will be explained. Additionally, in this case there is a first-order effect of social security on labor supply as the forced-savings constraint just begins to bind, but one that falls as the constraint becomes tighter. Once again, the effect of social security is qualitatively different from that of a tax upon a tax.

Section 3 analyzes the taxation of capital. As noted, capital taxation or subsidization is modeled as a differential tax on consumption in the two periods. Furthermore, to abstract from changes in the level of taxation, it is assumed that, when the tax on second-period consumption is increased (reduced), the tax on first-period consumption is reduced (increased) so that the same amount of revenue is raised for a given amount of labor income. It is first shown that, as one would expect, capital subsidization opposes the effect of myopia on consumption allocations, which raises welfare. Regarding labor supply, the effects are analogous to those of social security. For myopic labor supply, there is no effect of capital taxation or subsidization on labor supply at the point at which a differential is first introduced. But with nonmyopic labor supply, there is a first-order effect of the same sign and analogous magnitude to that arising under social security's forced savings. This section also considers the implications of heterogeneity in susceptibility to myopia. Capital subsidization improves the welfare of the myopic by reducing their intertemporal consumption misallocation but reduces the welfare of the nonmyopic by distorting theirs. Additionally, capital subsidization tends to redistribute from the myopic to the nonmyopic (at each level of earnings), the desirability of which depends on the form of the social 
welfare function and on the curvature of individuals' utility functions.

Section 4 examines the choice between social security and capital subsidization as remedies for myopia and also considers the relevance of liquidity constraints to the analysis. Section 5 offers concluding remarks.

\section{Social Security}

\subsection{Model}

Consider a two-period model in which individuals supply labor, $l$, in the first period at the wage $w$ and allocate disposable income between consumption, $c_{1}$ and $c_{2}$, in periods 1 and 2 . Suppose that utility takes the following form:

(1) $u\left(c_{1}, c_{2}, l\right)=\frac{c_{1}{ }^{1-\rho}}{1-\rho}+\delta \frac{c_{2}^{1-\rho}}{1-\rho}-z(l)$,

where $\delta$ is the subjective discount factor and $z$ measures the disutility of labor effort, with $z^{\prime}>0$ and $z^{\prime \prime}>0$. (To clarify, $\delta$ is taken here to be a real trait of individuals' utility, for purposes of assessing social welfare; myopia will be introduced separately below.) The positive constant $\rho$ is the coefficient of relative risk aversion, utility from consumption in each period taking the constant-relative-risk-aversion form (where it is understood that, when $\rho=1$, utility from consumption $c_{i}$ is instead given by $\ln c_{i}$ ). This functional form further implies that there is a constant elasticity of intertemporal substitution in consumption. Individuals are assumed to be subject to a linear income tax with marginal rate $t$ and grant $g$, and savings earn interest at the rate $r$, so their budget constraint (before we consider social security or capital taxation) is

(2) $c_{1}+\frac{c_{2}}{1+r}=(1-t) w l+g$.

The first-order condition for consumption allocation between the two periods by a nonmyopic individual (which can be determined by solving the budget constraint (2) for $c_{2}$, substituting it into expression (1), and differentiating) is

(3) $\frac{\partial u}{\partial c_{1}}=c_{1}^{-\rho}-\delta(1+r) c_{2}^{-\rho}=0$ or $\frac{c_{1}}{c_{2}}=\left(\frac{1}{\delta(1+r)}\right)^{1 / \rho}$.

Let $c_{1}$ * denote the optimal level of first-period consumption by a nonmyopic individual (which can be stated explicitly by simultaneously solving expressions (2) and (3) for $c_{1}$ and $c_{2}$ ).

To introduce myopia in a simple manner, suppose that, in allocating disposable income 
between $c_{1}$ and $c_{2}$, individuals behave as if they are maximizing the following variant of the utility function given by expression (1):

(4) $u\left(c_{1}, c_{2}, l\right)=\beta \frac{c_{1}^{1-\rho}}{1-\rho}+\delta \frac{c_{2}^{1-\rho}}{1-\rho}-z(l)$,

where the weight on first-period consumption $\beta$ is taken to exceed $1{ }^{4}$ This formulation could be taken to represent quasi-hyperbolic discounting, as in Laibson $(1996,1997)$, for the case of a two-period model, or other forms of myopia. The important point is that individuals' behavior is dictated by a different utility function (4) from that which defines their actual well-being (1), i.e., that which is relevant for assessing social welfare. ${ }^{5}$ The first-order condition for consumption allocation by a myopic individual is

$$
\text { (5) } \frac{\partial u}{\partial c_{1}}=\beta c_{1}^{-\rho}-\delta(1+r) c_{2}^{-\rho}=0 \text { or } \frac{c_{1}}{c_{2}}=\left(\frac{\beta}{\delta(1+r)}\right)^{1 / \rho} \text {. }
$$

Let $c_{1}{ }^{M}$ denote the optimal level of first-period consumption by a myopic individual. Comparing expressions (3) and (5), it is clear that $\beta>1$ implies $c_{1}{ }^{M}>c_{1}{ }^{*}$.

At this point, social security can be introduced into the model. This could be done fairly generally by letting $T^{S}(w l)$ denote the social security tax on labor earnings that individuals are required to pay in period 1 and $B^{S}(w l)$ as the level of social security benefits they receive in period 2, where benefits depend in some fashion on prior contributions. In order to isolate the effects of the forced-savings feature of social security from redistributive and revenue effects, it will be assumed that social security is actuarially fair, i.e., $T^{S}(w l)(1+r)=B^{S}(w l)$ for all $w l .{ }^{6}$ In

${ }^{4}$ It would also be natural to weight the disutility of labor, $z$, by $\beta$ because labor is supplied in the first period. Including such a weight would not materially affect the results below. (Specifically, each of the $z^{\prime}$ and $z^{\prime \prime}$ terms in expressions (7), (8), (19), (24), and (25), involving the cases with myopic labor supply, would be weighted by $\beta$, but the ultimate expressions of interest would be unchanged because this added weight would implicitly be in $d^{2} u / d l^{2}$ in the denominator of expressions (9), (10), (28), and (29).) Note also that, instead of weighting firstperiod sources of utility by $\beta$, one could weight second-period utility from consumption by a fraction less than one. The results would be nearly identical, the difference between the two formulations being in the cardinalization of utility as function of consumption. (Recall that the discount factor $\delta$ does not already reflect such a downward weighting of second-period consumption because $\delta$ is taken to be the true subjective discount rate, a feature of the normatively relevant utility function.)

${ }^{5}$ As has become familiar, myopia is being taken as a problem of self-control rather than as a feature of true utility (the latter being captured here by $\delta$ ).

${ }^{6}$ In the presence of a tax on labor income, the assumption that social security is actuarially fair is primarily a matter of notational convenience, for any difference between taxes and 
that case, social security would have no effect on the budget constraint (2), and thus on behavior, if individuals could freely borrow against (period 2) social security benefits and, furthermore, if despite their myopia they fully appreciated the availability of such benefits and had no compunction against borrowing. Thus, social security is only interesting when such borrowing is impossible or otherwise will not occur, as will be assumed throughout.

Accordingly, the (only) effect of social security in the present model is to constrain the amount individuals can consume in period 1 . For convenience, this upper bound on $c_{1}$ will be stated as a fraction of disposable income, so social security policy may be described simply yet completely by $\chi$, the minimum required fraction of savings. ${ }^{7}$ There is now the additional constraint

$$
\text { (6) } c_{1} \leq(1-\chi)[(1-t) w l+g] \text {. }
$$

If the constraint is binding, this expression is satisfied as an equality, which in turn for any given level of $l$ dictates the allocation of disposable income between $c_{1}$ and $c_{2}$.

If labor supply was unaffected by social security, welfare analysis would be straightforward. Raising $\chi$ has no effect until the point at which the constraint (6) begins to bind, i.e., the point at which the level of $c_{1}$ that satisfies (6) as an equality just equals $c_{1}{ }^{M}$. As $\chi$ is raised further, $c_{1}$ will fall. This initially produces a first-order welfare gain because $c_{1}{ }^{M}>c_{1}{ }^{*}$, and raising $\chi$ continues to produce such a gain until $c_{1}$ just equals $c_{1}{ }^{*}$. (The value of $\partial u / \partial c_{1}$ given by expression (3) is negative when $c_{1}>c_{1}{ }^{*}$.) In this respect, the forced savings that results from social security can be viewed as a substitute for a commitment technology that myopic

expected benefits at a given income level could instead be understood as a component of the labor income tax.

${ }^{7}$ Other formulations of social security could be analyzed, including one in which the bound is a fraction of earnings, $w l$, and another in which the bound is a fraction of after-tax earnings, $(1-t) w l$ (which differ from disposable income on account of $g$ ). For any given tax rate $t$, these two formulations are equivalent to each other, and the effect of changing the bound differs between the two cases only in magnitude because raising the latter bound (on after-tax earnings) one unit has a smaller effect than raising the former bound (on before-tax earnings) when $t>0$. Analysis of these two cases yields results qualitatively similar to those of the case considered in the text. Note that including $g$ in the quantity that is subject to forced savings, as is done here, has the effect that forced savings are a constant fraction of disposable income at all income levels, whereas the other formulations would make forced savings a rising fraction of disposable income (because the grant $g$, exempt from the forced-savings requirement in the alternative formulations, is a greater share of disposable income for lower-income individuals). Alternatively, if the grant payment was divided between the two periods (and borrowing against it was impossible), these two alternative models would be even closer to the present model. 
individuals would employ to reduce their level of $c_{1}$ if they had the ability to do so. ${ }^{8}$

In subsequent discussion, attention will largely be confined to levels of $\chi$ sufficiently high that the constraint binds (for lower values of $\chi$, since there is no effect on consumption, there can be no effect on labor supply) but not so high as to force $c_{1}$ below $c_{1}{ }^{*}$. The question to be explored is whether the effect of raising $\chi$ on labor supply reinforces or detracts from (or has no effect on) the welfare gains from forced savings in reallocating consumption between the two periods.

Two subcases regarding the effects of social security on labor supply should be distinguished: When individuals' labor supply decisions are subject to the same myopia that determines the allocation of consumption between periods, and when these decisions are rational in the sense that individuals not only understand that they will allocate their earnings myopically but also appreciate what their realized utility actually will be (i.e., that such an allocation involves too high a level of $c_{1}$ ). Both cases are of potential interest in light of the fact that myopic behavior is not that well understood and the recognition that myopia is context specific. ${ }^{9}$ Note specifically that the effect of myopia on labor supply may depend on the nature of the decision in question: Decisions about whether to pursue higher education or what job to choose from among many that require different effort levels may perhaps be made nonmyopically, whereas the same individuals may forgo overtime opportunities because of the immediate temptation to go out with friends or home to watch favorite television shows. For simplicity, analysis will focus on the two pure cases, beginning with that in which the same behavioral utility function (4) determines both consumption allocation and labor supply.

\subsection{Myopic Labor Supply}

As stated, the present assumption is that individuals' labor supply decision is also myopic in the sense that it is determined by maximizing utility as defined in expression (4) rather than as defined in expression (1). It should be emphasized that individuals are nevertheless assumed to appreciate that their consumption allocations are myopic in the same sense. In some respects, this assumption seem natural; one might say that such myopic individuals only know of one utility function in period 1, and that is the myopic one. In addition, it is the only case of analytical interest because otherwise individuals would not expect social security to be binding

${ }^{8}$ For individuals who already can commit to lower levels of $c_{1}$, social security would have no effect until the constraint began to bind on them, i.e., until first-period consumption is forced lower than the level to which they can successfully commit themselves. For simplicity, it is assumed that no private commitment technologies exist.

${ }^{9}$ For example, some individuals employ commitment devices (automatic contributions to retirement accounts, not purchasing types of food they know they will overeat), many fail to borrow (fully or at all) from increased home equity despite their tendency to consume all of their paychecks, and savings behavior may be influenced by modest changes in framing, such as when individuals' contributions to 401(k) plans depend on what contribution, if any, is specified as the default. On the latter, see Madrian and Shea (2001) and Choi et al. (2004). 
on themselves and thus there would be no effect on labor supply (keeping in mind that attention is focused on the case in which $\chi$ is not set so high as to force $c_{1}$ below $\left.c_{1}{ }^{*}\right){ }^{10}$

When the forced-savings constraint is binding, expression (6), holding as an equality, determines $c_{1}$ as a function of $l$. The value of $c_{2}$ as a function of $l$ can be determined by substituting for $c_{1}$ in the budget constraint (2), yielding $c_{2}=\chi[(1-t) w l+g](1+\mathrm{r})$. The first-order condition for labor supply in this case is

$$
\text { (7) } \frac{d u}{d l}=\beta c_{1}^{-\rho}(1-\chi)(1-t) w+\delta(1+r) c_{2}^{-\rho} \chi(1-t) w-z^{\prime}=0 \text {. }
$$

(Throughout, primes denote derivatives.) Differentiating this expression with respect to $\chi$ and rearranging terms yields

(8) $l_{\chi}=(1-t) w X$

$$
\frac{\beta c_{1}^{-\rho}\left\{1-\rho c_{1}^{-1}(1-\chi)[(1-t) w l+g]\right\}-\delta(1+r) c_{2}^{-\rho}\left\{1-\rho c_{2}^{-1} \chi[(1-t) w l+g](1+r)\right\}}{-\rho \beta c_{1}^{-\rho-1}(1-\chi)^{2}(1-t)^{2} w^{2}-\rho \delta(1+r)^{2} c_{2}^{-\rho-1} \chi^{2}(1-t)^{2} w^{2}-z^{\prime \prime}}
$$

where $l_{\chi}$ denotes $d l / d \chi$. Observe first that each term in braces in the numerator reduces to $1-\rho$ because $c_{i}^{-1}$ is followed by the expression for the respective $c_{i}$. When this common term is factored, what remains is equal to $\left(\partial u / \partial c_{1}\right)^{M}$, the partial derivative of utility with respect to $c_{1}$ for myopic individuals, as indicated by expression (5). Finally, the denominator can be shown to be equal to $d^{2} u / d l^{2}$ (from differentiating expression (7), i.e., for the present case of myopic labor supply). Accordingly, expression (8) simplifies to

(9) $l_{\chi}=\frac{(1-\rho)(1-t) w\left(\partial u / \partial c_{1}\right)^{M}}{d^{2} u / d l^{2}}$.

To interpret this expression, note first that the denominator must be negative at the individual's optimum (and it can readily be shown to be strictly negative for all $l$ in any event). Second, observe that the presence of the term $\left(\partial u / \partial c_{1}\right)^{M}$ in the numerator indicates that, as the constraint just begins to bind, the effect on labor supply (in whichever direction it may be) will be negligible. This result indicates that an actuarially fair tax on present disposable income to

${ }^{10}$ To state that there is no analytical interest in the alternative assumption that consumption myopia is unanticipated does not mean that it could not be of practical interest. If individuals did behave in this alternative manner, social security would raise welfare through improved consumption allocation, and no further analysis would be required to take into account effects on labor supply. 
finance forced savings does not effect labor supply in a manner qualitatively or (in general) quantitatively similar to that of further raising the marginal tax rate on current earnings, even though individuals are assumed to be myopic.

As the constraint becomes tighter (as $\chi$ increases once the constraint binds), $\left(\partial u / \partial c_{1}\right)^{M}$ becomes (more) positive. The reason is that this derivative reflects myopic individuals' perceived marginal utility from raising $c_{1}$ rather than their actual marginal utility. When the social security forced-savings constraint is binding, $c_{1}$ is less than what myopic individuals would choose, so the perceived marginal utility of raising $c_{1}$ further would be positive. Accordingly, $l_{\chi}$ is negative (positive) - i.e., tightening the forced-savings constraint reduces (increases) labor supply - if $\rho<1(\rho>1)$.

The intuition for this result can be understood by decomposing two effects (indicated by the " 1 " and the " $-\rho$ " in the leading term 1- $\rho$ ). A direct effect arises from more forced savings. When labor supply decisions reflect the same myopia as do individuals' first-period consumption allocation decisions, forcing an incremental reallocation of consumption toward period 2 is viewed as undesirable. Hence, the perceived return to labor effort falls.

An indirect effect is due to changes in relative marginal utilities of consumption in the two periods. As $\chi$ is increased, the consumption reallocation toward period 2 changes the marginal utility of consumption in each period, making it higher in period 1 and lower in period 2. Because first-period rather than second-period consumption is perceived as too low, the reallocation changes the (perceived) marginal utility of consumption more in the first period than in the second. (Stated precisely, the third derivative of utility as a function of consumption is positive, so the magnitude of the second derivative is greater when consumption is (perceived to be) low, as it is here in the first period, than when it is high, as in the second period.) When relative risk aversion is low, specifically, when $\rho<1$, this latter effect is less than the direct effect due to consumption being perceived to be less well allocated between the two periods, so the overall perceived marginal benefit of increasing labor effort falls. However, when risk aversion is high, $\rho>1$, the latter effect dominates, so labor effort rises. ${ }^{11}$ In other words, when $\rho>1$, the fact that social security makes earnings seem less attractive is outweighed by the fact that the forced reduction in $c_{1}$ greatly increases the perceived marginal value of first-period consumption, which can only be raised, partially restoring it to its unconstrained level, by working more. When $\rho<1$, this latter effect is present but insufficient to outweigh the direct reduction in the value of consumption.

${ }^{11}$ Formally, this condition and analysis are close to what would be applicable if one were addressing the question of how generous should be allocations of social resources to a twoperson family when the two family members do not share the resources equally. This coincidence should not be surprising. After all, with myopia, it is often stated that individuals behave as if there are two selves, see, for example, Thaler and Shefrin (1981); in the case of unequal sharing in the family, there literally are two persons, one of which is given less weight than the other. 
These results may be summarized as follows:

Proposition 1: When individuals' consumption allocation and labor supply decisions are subject to myopia, the effect on labor supply of tightening the social security forced-savings constraint is:

(a) zero as the constraint just begins to bind, but thereafter is nonzero (unless $\rho=1$ ) and

(b) negative, if $\rho<1$, and

(c) positive, if $\rho>1$.

Further illumination regarding the difference between the social security "tax" (i.e., the amount paid in period 1, as a function of $w l$, to fund consumption in period 2) and the income tax (also a positive function of $w l$ ) can be gleaned by comparing $l_{\chi}$ to $l_{t}$. For the latter, one can differentiate expression (7) with respect to $t$, rearrange terms, and make some substitutions to yield

(10) $l_{t}=$

$$
\frac{(1-\rho) w\left[(1-\chi) \beta c_{1}^{-\rho}+\chi \delta(1+r) c_{2}^{-\rho}\right]+\rho w g\left[(1-\chi)^{2} \beta c_{1}^{-\rho-1}+\chi^{2} \delta(1+r)^{2} c_{2}^{-\rho-1}\right]}{d^{2} u / d l^{2}} .
$$

To compare $l_{t}$ to $l_{\chi}$, focus initially (and primarily) on how the first term in the numerator on the right side of expression (10) compares to the numerator of the right side of expression (9). The term in brackets in the first term of (10) is positive, as is the value of $\left(\partial u / \partial c_{1}\right)^{M}$ in (9) (when considering the range in which the constraint is binding). Likewise, the leading factors both have the term $1-\rho$, so they also have the same sign. However, the terms in brackets themselves are quite different. Raising $t$ reduces consumption in both periods (by $1-\chi$ and $\chi$ in periods 1 and 2 , respectively), whereas raising $\chi$ reduces consumption in the first period while raising it in the second (see expression (5) for $\left.\left(\partial u / \partial c_{1}\right)^{M}\right)$. As noted when interpreting expression (9), the effect of the latter is nil at the point at which the constraint just begins to bind, rising thereafter, so the effect of the constraint is in this respect qualitatively different from that of a tax levied on top of a tax.

Observe that this difference persists even when myopia is significant. The reason is that myopic individuals do not have a higher marginal utility in period 1 once they have optimally from their perspective - adjusted their levels of consumption. At that point, they value increments to $c_{1}$ and to savings equally. (Another distinction between $l_{t}$ and $l_{\chi}$ is due to the second term in the numerator of expression (10), which has no corresponding component in expression (9): Raising $t$ pertains to only earned income and not the grant component $g$ of the 
linear income tax, so the income effect is adjusted accordingly. ${ }^{12}$ ) In conclusion:

Remark 1: When individuals' consumption allocation and labor supply decisions are subject to myopia, the effect on labor supply of tightening the social security forced-savings constraint is qualitatively different from that of increasing the existing income tax rate.

\subsection{Nonmyopic Labor Supply}

Assume instead that individuals' labor supply decisions are nonmyopic even though their consumption decisions are myopic. Specifically, suppose that individuals choose labor supply to maximize utility as defined by expression (1) rather than expression (4), but these labor supply decisions take into account that, when it comes time to decide upon consumption, the allocation will be given by expression (5), except to the extent constrained by social security, expression $(6) .{ }^{13}$

The analysis of this case is straightforward from the above derivation, although the conclusions differ. The first-order condition for labor supply is now

$$
\text { (11) } \frac{d u}{d l}=c_{1}^{-\rho}(1-\chi)(1-t) w+\delta(1+r) c_{2}^{-\rho} \chi(1-t) w-z^{\prime}=0 \text {. }
$$

This is identical to condition (7) for the case of myopic labor supply except that $\beta=1$.

Differentiating this expression with respect to $\chi$, rearranging terms, and making analogous substitutions to those used previously yields

$$
\text { (12) } l_{\chi}=\frac{(1-\rho)(1-t) w\left(\partial u / \partial c_{1}\right)}{d^{2} u / d l^{2}} \text {. }
$$

This condition is deceptively similar to expression (9) for the case of myopic labor supply, but it is importantly different because, in the numerator, $\left(\partial u / \partial c_{1}\right)^{M}$ from expression (5) is replaced by $\partial u / \partial c_{1}$ from expression (3), i.e., the effect on nonmyopic utility from raising $c_{1}$. When consumption decisions are anticipated to be myopic, and assuming that the social security parameter $\chi$ is in the range in which there is still overconsumption in period 1 , the value of $\partial u / \partial c_{1}$ is negative (whereas $\left(\partial u / \partial c_{1}\right)^{M}$ was positive) because, on account of myopia, $c_{1}$ has been raised

\footnotetext{
${ }^{12}$ As a result, there will be a range of $\rho$ somewhat in excess of one for which $l_{t}$ is negative even though $l_{\chi}$ for the myopic case is positive. See Chetty (forthcoming) on how unearned income influences the values of $\rho$ for which labor supply is upward sloping. Note that, in the present problem, despite myopia, it can be shown that labor supply is affected analogously by changing $t$ and by changing $w$, just as in the standard problem - that is, $l_{t}=-w l_{w} /(1-t)$.

${ }^{13}$ As mentioned in the preceding case, one could also consider the possibility that myopia is not anticipated when choosing labor supply, but then social security would have no effect on labor supply because the constraint would not be expected to bind.
} 
past the point at which the nonmyopic first-order condition for consumption is satisfied.

An immediate implication is that $l_{\chi}$ now has the same sign as $1-\rho$, rather than the opposite sign. That is, as more savings are forced, labor supply will rise (fall) if $\rho$ is less (greater) than 1. As before, the phenomenon has two components. First, when $\chi$ is increased, earnings are better allocated, which encourages labor effort. Because the labor supply decision is taken to be rational, the value of social security - as a substitute device making it possible for individuals de facto to commit to consume less - is positive in fact and is perceived as such. On the other hand, as $\chi$ is increased, the reduction in consumption misallocation changes the marginal utility of consumption in each period, making it higher in period 1 and lower in period 2. Because of the curvature of utility as a function of each period's consumption, the latter effect is greater. When $\rho<1$, this latter effect is less than the direct effect due to consumption being better allocated between the two periods, so the overall marginal benefit of increasing labor effort rises. However, when $\rho>1$, the latter effect dominates, so labor effort falls.

Another difference between the present case and that with myopic labor supply is that, there, $l_{\chi}=0$ as the forced-savings constraint just began to bind, whereas here this is not true: At that point, the marginal gain from consumption reallocation toward the future, which is taken into account in individuals' labor supply decisions, is at its greatest, and thus forced savings affects labor supply nontrivially (except when $\rho$ or $\beta$ is close to 1 ) from the moment the constraint begins to bind. This factor and, accordingly, the effect of forced savings on labor supply will equal zero not when the constraint just begins to bind but rather when $\chi$ reaches the point at which the magnitude of forced savings just equals its optimal (nonmyopic) level, i.e., when $c_{1}=c_{1}^{*}$. If $\chi$ were increased further, $\partial u / \partial c_{1}$ would reverse sign, becoming positive, and the sign of $l_{\chi}$ would reverse from whatever it had been when $\chi$ was lower. In this respect also, forcing additional savings has a qualitatively different effect from that of raising the tax rate. (One can also, as above, compare $l_{\chi}$ to $l_{t}$ explicitly; here, $l_{t}$ is as given by expression (10) except that $\beta=1$. The comparison is qualitatively different because $l_{\chi}$ is qualitatively different.)

These results may be summarized as follows:

Proposition 2: When individuals' consumption allocation decisions are subject to myopia but their labor supply decisions are not, the effect on labor supply of tightening the social security forced-savings constraint is:

(a) nonzero (unless $\rho=1$ ) as the constraint just begins to bind and thereafter-until consumption equals the nonmyopic optimum, at which point the effect is zero, after which it reverses from what is described in $(b)$ and $(c)$ - and in this initial range is

(b) positive, if $\rho<1$, and

(c) negative, if $\rho>1$.

In addition, juxtaposing the results for the cases of myopic and nonmyopic labor supply further reinforces the sense in which the effect of social security on labor supply differs from that of raising the marginal tax rate $t$ on labor income. The fact that the sign of the effect on labor supply from tightening the forced-savings constraint (whatever it might be) is opposite for 
myopic and nonmyopic labor supply decisions most clearly demonstrates that social security is qualitatively different. (Note that the reversal in sign applies independently to each of the two effects, the direct effect on the value of consumption and the indirect effect due to the curvature of the utility function.) Additionally, in each case, the magnitude of the effect is determined differently. For myopic labor supply, the initial marginal effect is zero - whereas adding a small ordinary tax on top of a preexisting tax has a first-order effect - and it grows in magnitude as the constraint tightens. For nonmyopic labor supply, the effect on labor supply (in whichever direction) is initially first-order and tends to fall (rather than rising) as more savings is forced, reaching zero when forced savings equal the nonmyopic savings optimum (after which the sign of the effect reverses from whatever it was). ${ }^{14}$

As previously noted, an important part of the explanation for these differences between forced savings and taxation is that, even with significant myopia that leads to substantial overallocation of disposable income to $c_{1}$, the result of the misallocation is an increase in the actual and perceived marginal utility of $c_{2}$, sufficiently so that, at the unconstrained myopic optimum, the individual is indifferent between reallocations of consumption between the two periods. Hence, forcibly reallocating some consumption to period 2 does not act at all like a tax, at least initially, in the myopic labor supply case and is viewed as a benefit (rather than as a cost, as with a tax) in the nonmyopic labor supply case. Although these features change as the constraint tightens, they do not immediately vanish. In conclusion:

Remark 2: When individuals' consumption allocation decisions are subject to myopia but their labor supply decisions are not, the effect on labor supply of tightening the social security forced-savings constraint is qualitatively different from that of increasing the existing income tax rate.

\section{Taxation of Capital Income}

\subsection{Model}

This section will analyze the same two-period model used in section 2 for purposes of analyzing social security. The only difference is that, instead of introducing a constraint (6) on first-period consumption, differential commodity taxation will be examined. As in standard models of commodity taxation, suppose the government can impose a tax $\tau_{i}$ on each of the commodities $c_{i}$ (corresponding to consumption in each period). For convenience, let $\theta_{i}=1+\tau_{i}$ denote the full price facing consumers. Accordingly, the budget constraint (2) can be rewritten as

${ }^{14}$ Of the two cases, social security is more tax-like when labor supply is myopic, for individuals perceive its mandate to be undesirable, and increasingly so as its magnitude rises (although, as noted previously, there are still substantial qualitative differences). 


$$
\text { (13) } \theta_{1} c_{1}+\frac{\theta_{2} c_{2}}{1+r}=(1-t) w l+g \text {. }
$$

Although it is conventional to think of a tax on capital income as applying to the interest rate $r$, the present formulation is equivalent and eases exposition and interpretation. (If the second term on the left side of (13) was written instead as $c_{2} /\left[1+r\left(1-\tau_{r}\right)\right]$, where $\tau_{r}$ is the tax rate on interest, one can let $\theta_{2}$ equal $(1+r) /\left[1+r\left(1-\tau_{r}\right)\right]$, which produces expression (13) as the budget constraint.)

Because we wish to focus on the effect of differential commodity taxation on consumption, utility, and labor supply, abstracting from effects on the overall level of taxation (revenue), it will be useful to consider a particular policy experiment: As $\theta_{2}$ is increased, it is assumed that $\theta_{1}$ is decreased to keep the present value of revenue raised from commodity taxation constant, under the hypothetical assumption that labor supply is unchanged. (Instead of adjusting $\theta_{1}$, one could adjust $t$ and derive analogous results, for it is familiar that changing the overall level of commodity taxes - keeping consumer price ratios, here $\theta_{1} / \theta_{2}$, constant - is equivalent to changing the level of income taxation. Holding $t$ constant and making all the adjustments through the $\theta_{i}$ 's has the virtue of keeping clear both that the overall level of taxation is fixed and, relatedly, that the only change involves relative taxation of consumption in each period.)

Furthermore, it will be convenient to follow the practice in much of the literature on optimal commodity taxation by focusing on local effects, in particular, raising $\theta_{2}$ from a starting point at which $\theta_{1}=\theta_{2}=1 .{ }^{15}$ Under these assumptions, to determine the required adjustment to $\theta_{1}$, one can differentiate an expression for (the present value of) commodity tax revenue, which is $\left(\theta_{1}-1\right) c_{1}+\left(\theta_{2}-1\right) c_{2} /(1+r)$, with respect to $\theta_{2}$, set it equal to zero, and evaluate the result at $\theta_{1}=\theta_{2}=1$, which yields

$$
\theta_{1}^{\prime}=-\frac{c_{2}}{c_{1}(1+r)}
$$

(Throughout this section, primes denote derivatives with respect to $\theta_{2}$, except for $z^{\prime}$, where the derivative as before is with respect to $l$.)

\subsection{Constant Labor Supply}

The effect of social security on consumption in each period and thus on the welfare of myopic individuals, ignoring effects on labor supply, was immediate. Because the effect of differential commodity taxation is not quite as straightforward and the details will prove useful for subsequent analysis, we begin by examining explicitly the case in which labor supply is

\footnotetext{
${ }^{15}$ In the present setting, analysis of further deviations would require recalibration of the revenue-neutral tax adjustment $\left(\theta_{1}{ }^{\prime}\right)$ to account for the extent of the change in $c_{1}$.
} 
imagined to be held constant.

To determine the first-order condition for consumption by a myopic individual, we can use the budget constraint (13) to solve for $c_{2}$, which equals $\left[(1-t) w l+g-\theta_{1} c_{1}\right](1+\mathrm{r}) / \theta_{2}$, substitute into expression (4) for perceived utility of the myopic consumer, and differentiate:

(15) $\frac{\partial u}{\partial c_{1}}=\beta c_{1}^{-\rho}-\frac{\theta_{1}}{\theta_{2}} \delta(1+r) c_{2}^{-\rho}=0$ or $\frac{c_{1}}{c_{2}}=\left(\frac{\theta_{2}}{\theta_{1}} \frac{\beta}{\delta(1+r)}\right)^{1 / \rho}$.

This condition, in turn, can be differentiated with respect to $\theta_{2}$ :

$$
\begin{aligned}
\frac{\partial^{2} u}{\partial \theta_{2} \partial c_{1}}= & -\rho \beta c_{1}^{-\rho-1} c_{1}^{\prime}-\delta(1+r) c_{2}^{-\rho}\left[\frac{\theta_{2} \theta_{1}^{\prime}-\theta_{1}}{\theta_{2}^{2}}\right] \\
& -\rho \frac{\theta_{1}}{\theta_{2}} \delta(1+r)^{2} c_{2}^{-\rho-1}\left[\frac{\theta_{2}\left(\theta_{1} c_{1}^{\prime}+c_{1} \theta_{1}^{\prime}\right)+\left[(1-t) w l+g-\theta_{1} c_{1}\right]}{\theta_{2}^{2}}\right]=0 .
\end{aligned}
$$

To simplify, use the fact that we are evaluating this derivative at $\theta_{1}=\theta_{2}=1$, that $\theta_{1}{ }^{\prime}$ is given by expression (14), that $c_{2}$ is determined by the budget constraint (13), and make use of the firstorder condition (15), allowing us to state

(17) $c_{1}^{\prime}=\frac{\beta c_{1}^{-\rho-1}[(1-t) w l+g]}{\rho \beta c_{1}^{-\rho-1}+\rho \delta(1+r)^{2} c_{2}^{-\rho-1}}$.

As expected, $c_{1}{ }^{\prime}>0$, as the numerator and denominator of expression (17) are both positive (the denominator is the negative of $\partial u^{2} / \partial c_{1}^{2}$ ). Noting the existence of partially common factors and making further use of the first-order condition (15) and the budget constraint (13), this can be further simplified to

(18) $c_{1}^{\prime}=\frac{c_{2}}{\rho(1+r)}$.

As expression (18) indicates, $c_{1}$ changes more in response to an increase in $\theta_{2}$ the smaller is the curvature of the utility function, indicated by $\rho$ (which, as noted, in this model is the coefficient of constant relative risk aversion and also $1 / \rho$ indicates the constant rate of intertemporal substitution). It is interesting to compare this effect to what might be called the mechanical effect of increasing $\theta_{2}$ on $c_{1}$, i.e., the rate at which consumption of $c_{1}$ would change if 
savings were held constant. The higher tax in period 2 and lower tax in period 1 would, in this respect, cause $c_{2}$ to fall and $c_{1}$ to increase, the latter at the rate of $c_{2} /(1+r)$. Accordingly, $c_{1}{ }^{\prime}$ simply equals the mechanical effect divided by $\rho$. When risk aversion (curvature) is low (below 1), individuals raise $c_{1}$ by more than indicated by the mechanical effect - i.e., they reduce savings - and when risk aversion is high (above 1 ), they raise $c_{1}$ by less - i.e., they increase savings (despite that fact that $\theta_{2} / \theta_{1}$ is higher).

Consistent with intuition, when individuals are myopic, it is optimal to reduce $\theta_{2}$ from its benchmark level, i.e., to employ a capital subsidy, in order to induce a decrease in first-period consumption, which is too high relative to what would be ideal according to the normative utility function (1). When capital is subsidized, individuals have fewer resources available in the first period and more in the second, which mechanically produces the desired effect - i.e., it would result even if individuals were unaware of the change and simply saved as they had previously. Under present assumptions, however, the increase in savings could be more or less, depending on the curvature of utility with respect to consumption. Next we examine how the desirability of taxing or subsidizing capital in the present setting is influenced by labor supply effects.

\subsection{Myopic Labor Supply}

Following the approach used when analyzing social security, it is now assumed that individuals, in choosing labor supply, are maximizing myopic utility, expression (4), and that they are aware that their consumption decisions are myopic as well. ${ }^{16}$ The first-order condition for labor supply in this case is

(19) $\frac{d u}{d l}=\beta c_{1}^{-\rho} \frac{d c_{1}}{d l}+\delta c_{2}^{-\rho} \frac{d c_{2}}{d l}-z^{\prime}=0$.

To determine the $d c_{i} / d l$ 's and for subsequent analysis, it is useful to introduce some additional notation. Let $y=(1-t) w l+g$ (disposable income, as given on the right side of the budget constraint (13)), and let $\Omega$ equal the right side of the latter expression in (15), which implies that $\Omega$ will also equal $c_{1} / c_{2}$. One can solve expressions (13) and (15) simultaneously, which yields

${ }^{16}$ Unlike in the case of social security, it would not be analytically trivial to consider the alternative assumption that individuals are myopic when choosing labor supply but do not anticipate being myopic when choosing consumption. If one followed the subsequent derivations mutatis mutandis, it would be seen that the same result obtains (in sharp contrast to the case with social security). 
(20) $c_{1}=\frac{y}{\theta_{1}+\theta_{2} / \Omega(1+r)}$, and

(21) $c_{2}=\frac{y}{\theta_{1} \Omega+\theta_{2} /(1+r)}$.

Therefore,

(22) $\frac{d c_{1}}{d l}=\frac{(1-t) w}{\theta_{1}+\theta_{2} / \Omega(1+r)}=c_{1} \frac{(1-t) w}{y}$, and

(23) $\frac{d c_{2}}{d l}=\frac{(1-t) w}{\theta_{1} \Omega+\theta_{2} /(1+r)}=c_{2} \frac{(1-t) w}{y}$.

Accordingly, expression (19) can be rewritten as

(24) $\frac{d u}{d l}=\left[\beta c_{1}^{1-\rho}+\delta c_{2}^{1-\rho}\right] \frac{(1-t) w}{y}-z^{\prime}=0$.

To find how labor supply is affected by changing $\theta_{2}$, we can differentiate as follows:

(25) $\frac{d^{2} u}{d \theta_{2} d l}=\left[\beta c_{1}^{1-\rho}+\delta c_{2}^{1-\rho}\right]\left(\frac{-(1-t)^{2} w^{2} l_{\theta_{2}}}{y^{2}}\right)$

$$
+\left(\frac{(1-t) w}{y}\right)\left[(1-\rho) \beta c_{1}^{-\rho} c_{1}^{\prime}+(1-\rho) \delta c_{2}^{-\rho} c_{2}^{\prime}\right]-z^{\prime \prime} l_{\theta_{2}}=0 .
$$

(Recall that primes denote derivatives with respect to $\theta_{2}$, except for $z^{\prime \prime}$.) Differentiation of expressions (20) and (21) with respect to $\theta_{2}$, making appropriate substitutions, allows one to determine that 
(26) $c_{1}^{\prime}=\frac{(1-t) w c_{1}}{y} l_{\theta_{2}}+\frac{c_{2}}{\rho(1+r) \theta_{1}}$, and

(27) $c_{2}^{\prime}=\frac{(1-t) w c_{2}}{y} l_{\theta_{2}}-\frac{c_{2}}{\rho \theta_{2}}$.

Evaluating these expressions at $\theta_{1}=\theta_{2}=1$, one can see that the second terms in each simply indicate the effect of raising $\theta_{2}$ when labor supply was held constant. (For example, compare expressions (26) and (18).) The first terms depict the effect of raising $\theta_{2}$ on labor supply multiplied by the corresponding expenditure shares.

If one substitutes using expressions (26) and (27) in expression (25) and rearranges terms, the result is

(28) $l_{\theta_{2}}=\frac{-\left(\frac{1-\rho}{\rho}\right)\left(\frac{(1-t) w c_{2}}{y(1+r)}\right)\left[\beta c_{1}^{-\rho}-\delta(1+r) c_{2}^{-\rho}\right]}{d^{2} u / d l^{2}}$.

The term in square brackets is simply the first-order condition for myopic individuals' consumption allocation decisions, $\left(\partial u / \partial c_{1}\right)^{M}$, from expression (5). Therefore,

(29) $l_{\theta_{2}}=\frac{-\left(\frac{1-\rho}{\rho}\right)\left(\frac{(1-t) w c_{2}}{y(1+r)}\right)\left(\partial u / \partial c_{1}\right)^{M}}{d^{2} u / d l^{2}}$.

Because individuals' first-order condition for consumption is satisfied, it follows that $l_{\theta_{2}}=0$. This result is as one would expect: As one just begins to raise $\theta_{2}$ (and lower $\theta_{1}$ as indicated by expression (14)), starting from $\theta_{1}=\theta_{2}=1$, the resulting change in the allocation of consumption has no first-order effect on myopic individuals' (perceived) utility; hence, the return to labor effort is unaffected. This result is analogous to that for social security when the constraint just begins to bind. (Compare expressions (29) and (9).) Accordingly, we can state:

Proposition 3: When individuals' consumption allocation and labor supply decisions are subject to myopia, raising the relative tax rate on second-period consumption (i.e., in a constantrevenue manner) has no effect on labor supply at the point of no differential taxation. 


\subsection{Nonmyopic Labor Supply}

As with social security, we now consider the case in which individuals' labor supply decisions are nonmyopic - they choose labor effort to maximize expression (1) rather than expression (4) - even though their consumption choices are myopic, a fact that they anticipate. ${ }^{17}$ Analysis of this case closely parallels that for myopic labor supply. Specifically, expressions (19) through (28) would be unaltered except for the fact that the $\beta$ 's in expressions (19), (24), (25) and (28) would be replaced by 1's. ${ }^{18}$ Thus, expression (29) is replaced by

(30) $l_{\theta_{2}}=\frac{-\left(\frac{1-\rho}{\rho}\right)\left(\frac{(1-t) w c_{2}}{y(1+r)}\right)\left(\partial u / \partial c_{1}\right)}{d^{2} u / d l^{2}}$.

Expression (30) differs from expression (29) because we now have the nonmyopic derivative of utility with respect to $c_{1}$ in the numerator. Because of myopia in the actual choice of consumption, this derivative is negative (individuals' initially are overconsuming in the first period) - until $c_{1}$ is reduced to $c_{1}^{*}$, but here we are only considering a marginal increase in $\theta_{2}$. Because the denominator is also negative, the sign of $l_{\theta_{2}}$ will be the same as that of $\rho-1$. The interpretation is the same as in the case of social security with nonmyopic labor supply. The direct effect of raising $\theta_{2}$, i.e., of taxing capital (second-period consumption) is to worsen the already distorted consumption allocation, which reduces the return to labor effort. (This corresponds to the "- 1 " in $\rho-1$.) The indirect effect is that, as the distortion worsens, there is a further drop in the marginal utility of first-period consumption and rise in the marginal utility of second period consumption. The latter effect is larger and, if $\rho>1$, exceeds the direct effect, causing labor supply to rise.

If differential commodity taxation is to be employed as a partial remedy for myopia, a capital subsidy would be contemplated, as discussed in subsection 3.2. This would increase labor supply when $\rho<1$ and decrease labor supply when $\rho>1$. This is the same result as with tightening the social security constraint in the case of nonmyopic labor supply. Indeed, a comparison of expressions (30) and (12) indicates that they are nearly identical. The opposite signs are due to the fact that raising social security contribution requirements (raising $\chi$ ) reduces $c_{1}$ whereas raising $\theta_{2}$ increases $c_{1}$. The other differences in the numerator reflect different scaling due to the differences in the policy experiments. ${ }^{19}$ Therefore, we have:

${ }^{17}$ If their myopic consumption choices were not anticipated, they would not find that a small change in capital taxation had other than a second-order effect on their consumption allocation, so labor supply would be unaffected, just as was the case with myopic labor supply.

${ }^{18}$ There are also $\beta$ 's implicit elsewhere, in particular, in the definition of $\Omega$; these remain unaffected because they indicate consumption myopia.

${ }^{19}$ In expression (30), $c_{2} / \rho(1+r)$ equals $c_{1}{ }^{\prime}$, as indicated by expression (18), reflecting the fact that, when capital taxation is changed, individuals are induced to adjust consumption (to an 


\section{Proposition 4: When individuals' consumption allocation decisions are subject to}

myopia but their labor supply decisions are not, raising the relative tax rate on second-period consumption (i.e., in a constant-revenue manner) has a nonzero effect on labor supply (unless $\rho=1)$ at the point of no differential taxation, which is

(a) negative, if $\rho<1$, and

(b) positive, if $\rho>1$.

\subsection{Heterogeneity}

It is plausible to suppose that individuals vary in their susceptibility to myopia. Such differences may be reflected in myopia per se (the level of $\beta$ ) as well as in their ability to employ commitment strategies to offset the effects of myopia. For simplicity, suppose that there are two types of individuals, some myopic (to the same degree) and some not.

Such heterogeneity implies that there will be a tradeoff in determining the optimal tax (subsidy) on capital. Beginning with the case in which there are no labor supply effects, a small capital subsidy will produce a first-order utility gain to the myopic but no first-order loss to the nonmyopic. As the subsidy rises, the extent of the gain to the former group will fall, and there will be an increasing first-order loss to the latter. Hence, the optimal subsidy would reflect a balance between these considerations.

Labor supply has already been examined for individuals exhibiting consumption myopia. For those who do not, it is clear that there will be no first-order effect of a small degree of capital subsidization on labor supply. The reasoning parallels that in subsection 3.3 for myopic labor supply by myopic consumers: Because the initial effect on reallocating consumption is secondorder, the return to labor is unchanged. Hence, regarding a small capital subsidy, the only labor supply effects will be attributable to myopic consumers with nonmyopic labor supply, so any adjustment for labor supply effects would be weighted by their fraction in the population.

In a complete optimal income tax analysis, one would also have to take into account distributive effects due to heterogeneity. Specifically, nonmyopic individuals will, ceteris paribus (for a given ability and earnings level) be better off than myopic individuals. ${ }^{20}$ This

extent that depends on the elasticity of intertemporal substitution and the level of consumption subject to tax). The only other difference between expressions (30) and (12) is the $y$ in the denominator of the numerator in expression (30). This reflects that $\chi$, the forced-savings minimum for social security, is applied to income as a whole; see expression (6).

${ }^{20} \mathrm{An}$ increase in capital subsidization that was designed to keep each group's tax payments constant (rather than merely the total) would involve a relative tax on the nonmyopic and transfer to the myopic because, ceteris paribus, the nonmyopic benefit more from subsidizing second-period consumption since theirs is greater. The simple increase in capital subsidization examined here can be understood as the combination of such a compensated increase and a direct (income-level-specific) transfer from the myopic to the nonmyopic. This feature explains the social welfare relevance of the heuristic arguments in the text that follows; as mentioned in note 
difference in well-being may seem to favor some redistribution from the nonmyopic to the myopic, and since the former save more than the latter, capital taxation rather than subsidization (or perhaps less subsidization than otherwise would be optimal) may be in order. This difference in utility levels is relevant, however, only to the extent that the social welfare function is strictly concave. For a utilitarian social welfare function (and, to a degree for others, short of maximin), it is differences in marginal utilities of consumption between the nonmyopic and myopic that count.

To determine how (actual) marginal utility depends on myopia (the level of $\beta$ ), we can take the derivative of utility given by expression (1) with respect to lump-sum income $g$, making use of expressions (20) and (21) for the $c_{i}$ 's (evaluated at $\theta_{1}=\theta_{2}=1$ ) and make appropriate substitutions:

$$
\frac{\partial u}{\partial g}=\frac{1}{y}\left[c_{1}^{1-\rho}+\delta c_{2}^{1-\rho}\right]
$$

Next, we can differentiate with respect to $\beta$ :

$$
\frac{\partial^{2} u}{\partial \beta \partial g}=\frac{1-\rho}{y}\left[c_{1}^{-\rho} \frac{\partial c_{1}}{\partial \beta}+\delta c_{2}^{-\rho} \frac{\partial c_{2}}{\partial \beta}\right]
$$

To determine the partial derivatives of the $c_{i}$ 's, we can again make use of expressions (20) and (21), which ultimately yields

$$
\text { (33) } \frac{\partial^{2} u}{\partial \beta \partial g}=\left(\frac{1-\rho}{\rho}\right)\left(\frac{c_{1} c_{2}}{y^{2} \beta(1+r)}\right)\left[c_{1}^{-\rho}-\delta(1+r) c_{2}^{-\rho}\right] \text {. }
$$

Finally, observe that the term in square brackets is simply $\partial u / \partial c_{1}$ from expression (3), nonmyopic individuals' first-order condition for allocating consumption. Hence, we can write

$$
\text { (34) } \frac{\partial^{2} u}{\partial \beta \partial g}=\left(\frac{1-\rho}{\rho}\right)\left(\frac{c_{1} c_{2}}{y^{2} \beta(1+r)}\right)\left(\partial u / \partial c_{1}\right) \text {. }
$$

To interpret expression (34), note that when $\beta=1$, that is, when individuals are not myopic, $\partial u / \partial c_{1}$ is their actual first-order condition, so the final term is zero. For $\beta>1, \partial u / \partial c_{1}$ is negative because $c_{1}$ is already too high from the perspective of normative utility. Therefore, the

2, no rigorous social welfare optimization is attempted. 
sign of the derivative in expression (34) is given by the sign of $\rho-1$. If $\rho<1(\rho>1)$, myopic individuals have a lower (higher) marginal utility of consumption, and on this account it would be optimal to redistribute away from (toward) such individuals, reinforcing (undercutting) the case for a capital subsidy. The intuition is that, because myopic individuals make poorer use of incremental consumption, their marginal utility tends to be lower, ceteris paribus; however, due to the curvature of utility, the rise in marginal utility attributable to the resources that are allocated to $c_{2}$ exceeds the fall in marginal utility of resources allocated to $c_{1}$, and when $\rho>1$ this effect dominates the direct effect.

\section{Discussion}

\subsection{Social Security versus Capital Subsidization}

Consider the choice between the use of social security and capital subsidization as remedies for myopia. In the case in which all individuals suffer equally from myopia, the two policies are quite similar. Social security forces additional savings whereas capital subsidization induces it. One could compare regimes that were scaled so as to have the same effect on firstperiod consumption, in which case the direct welfare effect with regard to improved consumption reallocation would be the same. Likewise, labor supply effects would be similar. (Recall, for example, the comparison of expressions (12) and (30) for the case of nonmyopic labor supply; the signs of the effects are the same and the only difference in magnitude is due to scaling, which is taken here to be equalized.)

The more important case involves heterogeneity, for example, the previously noted case in which some individuals are (equally) myopic and others are not. ${ }^{21}$ Social security, in the range considered, improves consumption allocations for the former group (and has the aforementioned effects on labor supply) and has no effect on the latter because the forced-savings constraint is not binding for them. By contrast, capital subsidization reduces first-period consumption of both groups. For the nonmyopic, this consequence is distortionary (once the subsidy becomes strictly positive). There would also be effects on labor supply, the direction depending on the curvature of the utility function. ${ }^{22}$

It is also interesting to consider the combined use of social security and capital subsidization. As the social security constraint becomes tighter, capital subsidization would tend to become less desirable: The favorable inducement for the myopic would become irrelevant, but the distortion of the nonmyopic would remain. Additionally, if capital subsidization were

\footnotetext{
${ }^{21}$ Individuals also may differ in whether their labor supply is myopic, in which case opposing labor supply effects would net to some extent, and in their preferences.

${ }^{22}$ Regarding the redistributive issue addressed in subsection 3.5, note that although general (income-based) redistribution can be accomplished through forced savings, capital taxation is distinctive in affecting the within-income-group distribution between myopic and nonmyopic individuals.
} 
already employed, the effect of social security would be nil until the now-later point at which the forced-savings constraint begins to bind.

\subsection{Liquidity Constraints}

The possibility that some individuals are liquidity constrained, especially when young, is relevant to the consideration of myopia, forced savings, and capital taxation. See, for example, Hubbard and Judd $(1986,1987)$. Although liquidity constraints are moot in the present model (because all lifetime income is received in the first of the two periods), they could emerge as important in a natural extension with multiple years of work.

The effect of liquidity constraints on consumption misallocation depends on individuals' true utility functions, their myopia, and the way liquidity constraints bind. For the myopic, liquidity constraints might increase utility by reducing the extent of overconsumption in early years. If liquidity constraints force consumption to be too low, however, social security's forcedsavings constraint can only hurt, although it may not be binding on such individuals. It would be binding if earnings in early years were very low relative to lifetime income and borrowing was impossible. As a consequence, it may be desirable to defer forced-savings requirements until individuals are at a stage at which earnings are greater and consumption needs are lower, mirroring optimal retirement savings patterns of nonmyopic individuals.

Capital subsidization would not induce further reductions in early consumption of liquidity-constrained individuals. Indeed, capital taxes or subsidies - imposed as a function of unearned income - would be irrelevant for individuals who neither borrow nor save (and who would not be induced to do so by the tax or subsidy). It would be possible to differentially tax consumption in different periods (tax rates could depend on age); then higher taxes in early years and lower taxes in later years would, through the mechanical effect described in subsection 3.2, reduce early consumption, which would be detrimental for liquidity-constrained individuals.

The analysis of labor supply, the focus here, is affected by liquidity constraints in a straightforward manner. Regarding individuals for whom the constraints are binding, neither social security nor capital subsidization affects consumption; hence, labor supply is unaffected as well. For individuals not bound by liquidity constraints, the effects of such policies on labor supply are as analyzed previously.

\section{Conclusion}

This article offers a preliminary analysis of the effects of social security and of capital taxation on labor supply in a model in which individuals exhibit myopia in their allocation of consumption over time. The questions are important given the belief that myopia may significantly influence individuals' decision-making and that myopia has a central role in justifying social security and policies toward the taxation of capital. To focus on core issues, a simple, two-period model with separable utility was employed, social security was taken to be 
actuarially fair, and capital taxation was adjusted in a manner that kept the overall level of taxation constant.

The effect of social security on labor supply was seen to depend on the curvature of individuals' utility functions and also on whether or not labor supply decisions are myopic in the same manner as consumption decisions are. Interestingly, although the sign of labor supply effects depends on the same parameters in each of the two cases regarding labor supply myopia, the effects are reversed in the two cases on account of the fact that the desirability of social security in reallocating consumption across periods is perceived in an opposite fashion. Furthermore, for myopic labor supply, the social security forced-savings constraint has no effect at the margin when it just begins to bind, but for nonmyopic labor supply, the effect is first order - although decreasing as the constraint becomes tighter. In many respects, the social security "tax" does not have the properties of a tax levied on top of a preexisting tax (here the labor income tax), even though individuals' myopia leads them to overweight the present, when the social security tax is levied, relative to the future, when actuarially fair benefits are paid.

Capital taxation contributes to the distortion of consumption allocations due to myopia, making capital subsidization appear attractive. Raising capital taxation shifts taxation from the present to the future in the present model (in which revenue raised at a given income level is held constant). In light of individuals' myopia, one might expect capital taxation to be attractive on this account, yet it does not reduce labor supply distortion in any straightforward manner. Instead, the effects of capital subsidization on labor supply are similar to those of social security and thus depend on the curvature of individuals' utility as well as on whether labor supply decisions are myopic.

In both settings, results that may at first seem counterintuitive are explained in significant part by the fact that, in the present model, even myopic individuals are assumed to engage in optimization. Their consumption allocations do not imply a preference for present consumption at the margin because their myopia has already skewed consumption toward the present until the point at which they are indifferent to marginal adjustments. Social security's forced-savings requirement, as it begins to bind, and capital taxation each influence consumption allocations beginning from that point.

This investigation suggests a number of avenues for further inquiry. Most obviously, the model could be extended in a number of ways; as section 4 notes, allowing additional periods of labor supply, nonconstant wage profiles, and liquidity constraints would complicate the welfare analysis, as does heterogeneity (briefly explored in subsection 3.5, with regard to capital taxation). In addition to comparing the welfare effects of social security and capital taxation (subsidization) on myopic individuals, other policies such as the structure of retirement plans could be examined.

Additionally, it is important to explore the implications of other behavioral assumptions. Bernheim (1994), Diamond (2004), and some others suggest that retirement savings may be suboptimal because of the sheer complexity of retirement planning and individuals' inexperience. 
To analyze this problem, it would be necessary to define more precisely the structure of individuals' errors in order to examine the effects of social security, capital taxation, or other policies on labor supply and welfare. ${ }^{23}$ In this setting, it might be supposed that some individuals would save too little and others would save too much; the latter may be unaffected by social security but further distorted by capital subsidization.

It would also be instructive to introduce uncertainty regarding future earnings and health status. In addition to influencing the analysis of the labor supply effects of social security retirement schemes and capital taxation, it would also be appropriate to investigate other forms of social insurance, such as for unemployment and disability. One might expect myopia to operate similarly because these sorts of social insurance programs, like social security retirement systems, tend to impose a present tax on earnings in order to finance future benefits, albeit statecontingent ones. ${ }^{24}$ Of course, additional features would be introduced as well.

Finally, the present analysis suggests some directions for empirical investigation. Study of the effects of taxation on labor supply sometimes treat social security taxation as cumulative with explicit labor income taxation, whereas analytically they should have qualitatively different effects. Given that the payroll taxes that finance social security are of a similar order of magnitude to labor income taxes, it is important to test whether and how their effects on labor supply differ. Moreover, the effects of both social security and capital taxation (subsidization) depend on whether or not labor supply is myopic in the same fashion as is consumption. This subject, however, has not been substantially explored; empirical work on myopia has tended to focus on ultimate intertemporal decisions such as savings rather than on intermediate decisions like labor supply, the return to which depends on such subsequent choices. Furthermore, the results here assume that myopia takes a particular form (one consistent with quasi-hyperbolic discounting, which has received some empirical support), but alternative consumption behavior may have different implications for labor supply. ${ }^{25}$

${ }^{23}$ One specific possibility is that some individuals underestimate and others overestimate the benefits they will receive, in which case social security acts like a labor income tax on the former and subsidy on the latter. Some other possibilities are the subject of a sequel in progress, tentatively entitled "Non-Optimizing Behavior, Social Security, and Labor Supply." Concerns about misunderstanding of benefits motivate suggestions to provide clearer statements to individuals of how their future benefits accrue as they work and also proposals to pre-fund social security in the form of defined contribution plans.

${ }^{24}$ The labor supply effects of political uncertainty of the sort measured by Dominitz, Manski, and Heinz (2003), concerning whether future benefits will be paid, would be quite different. Specifically, individuals might treat the perceived future deficiency as an additional tax on labor supply and be induced to over-save.

${ }^{25}$ One might study, for example, whether the sort of behavior documented by Madrian and Shea (2001) and Choi et al. (2004), wherein different default specifications for retirement plans lead to substantial changes in savings behavior, has similar implications for labor supply as do changes in social security. 
Four points seem clear: Myopia and related behavior may be empirically significant; such behavior is central to the analysis of social security and capital taxation, among other policies; labor supply considerations are likewise consequential; and, finally, myopia has important implications for labor supply. Taken together, these factors suggest that additional research in this area is warranted. 


\section{References}

Aguiar, Mark, and Hurst, Erik. “Consumption versus Expenditure." Journal of Political Economy, 2005, 113 no. 5: 919-948.

Atkinson, Anthony B. and Stiglitz, Joseph E. "The Design of Tax Structure: Direct Versus Indirect Taxation." Journal of Public Economics, 1976, 6:1-2: 55-75.

Auerbach, Alan J., and Kotlikoff, Laurence J. Dynamic Fiscal Policy. Cambridge, UK: Cambridge University Press, 1987.

Banks, James, Blundell, Richard, and Tanner, Sarah. "Is There a Retirement-Savings Puzzle?" American Economic Review, 1998, 88, no. 4:769-88.

Bernheim, B. Douglas. "Personal Saving, Information, and Economic Literacy: New Directions for Public Policy." In C.E. Walker, M. Bloomfield, and M. Thorning, eds., Tax Policy for Economic Growth in the 1990s. Washington, D.C.: American Council for Capital Formation, 1994: 53-78.

Bernheim, B. Douglas. "Taxation and Saving." In Alan J. Auerbach and Martin Feldstein, eds., Handbook of Public Economics. Vol. 3. Amsterdam: North-Holland, 2002: 1173-1249.

Bernheim, B. Douglas, and Rangel, Antonio. "Behavioral Public Economics: Welfare and Policy Analysis with Non-Standard Decision Makers.” National Bureau of Economic Research, NBER Working Papers: No. 11518, 2005.

Bernheim, B. Douglas, Skinner, Jonathan, and Weinberg, Steven. "What Accounts for the Variation in Retirement Wealth among U.S. Households?" American Economic Review, 2001, 91 no. 4:832-857.

Browning, Edgar K. "The Marginal Social Security Tax on Labor." Public Finance Quarterly, 1985,13 no. $3: 227-251$.

Burkhauser, Richard V., and Turner, John A. "A Time-Series Analysis on Social Security and Its Effect on the Market Work of Men at Younger Ages." Journal of Political Economy. 1978,86 , no. 4:701-715.

Burkhauser, Richard V. and Turner, John A. "Is the Social Security Payroll Tax a Tax?" Public Finance Quarterly, 1985, 13 no. 3:253-267.

Chetty, Raj. “A Bound on Risk Aversion Using Labor Supply Estimates.” American Economic Review (forthcoming).

Choi, James J., Laibson, David, Madrian, Brigitte C., and Metrick, Andrew. "For Better of 
Worse: Default Effects and 401(k) Savings Behavior." In David A. Wise, ed., Perspectives on the Economics of Aging. Chicago: University of Chicago Press, 2004. 81-121.

Diamond, Peter A. Social Security Reform. Oxford: Oxford University Press, 2002.

Diamond, Peter A. "Social Security." American Economic Review, 2004, 94 no. 1:1-24.

Diamond, Peter A., and Köszegi, Botond. "Quasi-Hyperbolic Discounting and Retirement." Journal of Public Economics, 2003, 87, no. 9-10:1839-1872.

Diamond, Peter A., and Mirrlees, James A. "A Model of Social Insurance with Variable Retirement." Journal of Public Economics, 1978, 10, no. 3:295-336.

Diamond, Peter A., and Mirrlees, James A. "Payroll-Tax Financed Social Insurance with Variable Retirement." Scandinavian Journal of Economics, 1986, 88, no. 1:25-50.

Diamond, Peter A., and Mirrlees, James A. "Social Insurance with Variable Retirement and Private Savings." Journal of Public Economics, 2007, 91, no. _:

Dominitz, Jeff, Manski, Charles F., and Heinz, Jordan. "Will Social Security Be There for You?': How Americans Perceive Their Benefits.” National Bureau of Economic Research, NBER Working Papers: No. 9798, 2003.

Engen, Eric M., Gale, William G., and Uccello, Cori E. "The Adequacy of Household Saving." Brookings Papers on Economic Activity, 1999, no. 2:65-187.

Feldstein, Martin. "The Optimal Level of Social Security Benefits." Quarterly Journal of Economics, 1985, 100, no. 2: 303-320.

Feldstein, Martin, and Liebman, Jeffrey B. "Social Security." In Alan J. Auerbach and Martin Feldstein, eds., Handbook of Public Economics. Vol. 4. Amsterdam: North-Holland, 2002: 2245-2324.

Gordon, Roger H. "Social Security and Labor Supply Incentives." Contemporary Policy Issues, 1983, no. 3:16-22.

Hubbard, R. Glenn, and Judd, Kenneth L. "Liquidity Constraints, Fiscal Policy, and Consumption." Brookings Papers on Economic Activity, 1986, no. 1:1-50.

Hubbard, R. Glenn, and Judd, Kenneth L. "Social Security and Individual Welfare: Precautionary Saving, Borrowing Constraints, and the Payroll Tax." American Economic Review, 1987, 77, no. 4:630-646.

Kotlikoff, Laurence J., Spivak, Avia, and Summers, Lawrence H. "The Adequacy of 
Savings." American Economic Review, 1982, 72 no. 5:1056-1069.

Laibson, David. "Hyperbolic Discount Functions, Undersaving, and Savings Policy." National Bureau of Economic Research, NBER Working Papers: No. 5635, 1996.

Laibson, David. "Golden Eggs and Hyperbolic Discounting." Quarterly Journal of Economics, 1997, 112 no. 2:443-477.

Madrian, Brigitte C., and Shea, Dennis F. "The Power of Suggestion: Inertia in 401(k) Participation and Savings Behavior." Quarterly Journal of Economics, 2001, 116 no. 4:11491187.

Moffitt, Robert A. "Life-Cycle Labor Supply and Social Security: A Time-Series Analysis." In Gary Burtless, ed., Work, Health, and Income among the Elderly. Washington, D.C.: Brookings Institution, 1987: 183-220.

Moore, James, and Mitchell, Olivia S. "Projected Retirement Wealth and Saving Adequacy." In Olivia S. Mitchell, P. Brett Hammond, and Anna M. Rappaport, eds., Forecasting Retirement Needs and Retirement Wealth. Philadelphia: University of Pennsylvania Press, 2000: 68-94.

Scholz, John Karl, Seshadri, Ananth, and Khitatrakun, Surachai. “Are Americans Saving 'Optimally' for Retirement?" National Bureau of Economic Research, NBER Working Papers: No. 10260, 2004.

Strotz, Robert H. 1956. "Myopia and Inconsistency in Dynamic Utility Maximization." Review of Economic Studies 23:165-180.

Thaler, Richard H., and Shefrin, H. M. 1981. “An Economic Theory of Self-Control.” Journal of Political Economy 89, no. 2:392-406. 